\title{
Expected Long-Term Labour Market Resilience and the European Union's Perceived Role \\ Results of an Online Policy Delphi
}

\author{
György Lengyel
}

Corvinus University of Budapest, Institute of Sociology and Social Policy

E-mail: gyorgy.lengyel@,uni-corvinus.hu

\section{Borbála Göncz}

Corvinus University of Budapest, Institute of Sociology and Social Policy

\author{
Lilla Tóth
}

Corvinus University of Budapest, Institute of Sociology and Social Policy

The 2008 crisis highlighted how fragile the labour markets of the European Union's member states were, while it also directed attention to the eventual further deepening of integration as a potential solution. Nevertheless, employment and labour market policy competences are still on the national level with relatively low EU intervention. In a recent study, we explored the role of the EU in facilitating potential policy solutions with regards to labour market resilience until 2030. The study focused on labour market experts' opinion, coming from different European countries; and took form of an online Policy Delphi Survey combined with backcasting to predict the importance and feasibility of policies concerning future challenges. The most important policies considered to be best suited to deal with the main challenges of the labour market in the EU until 2030 are education, investment in human and social capital and improvement of social policies and protection, including migration policy. The research revealed a systematic gap between the importance and feasibility of relevant solutions.

Keywords: European Union, labour market resilience, labour policy, policy competence, Delphi, backcasting

\section{JEL codes: J0}

\section{Introduction}

The 2008 global economic and financial crisis made clear the fragility of the labour markets of the European Union's member states. Some of the countries were better equipped to absorb economic shocks than others, which points to the different capacities of the different labour markets to adapt to an external shock. Furthermore, the crisis also enhanced the attention given to the European Union's role in dealing with the effect of the crisis and the eventual deepening of integration as a potential solution.

Nevertheless, employment and labour market policy competences are still on the national level with relatively low intervention of the EU. In this paper, we explore the possibilities of eventual further integration regarding labour market policies and the preferences for the nature and extent of the EU's participation. The paper focuses on labour 
market experts' opinion and presents the results of a three-rounds online Policy Delphi Survey.

Delphi, as a method, was designed to provide the benefits of a pooling and exchange of opinions, so that expert respondents can learn from each other's views, without the influence likely in conventional face-to-face settings. Delphi, as it originally was introduced and practised, tended to deal with technical topics and seek a consensus among a homogeneous group of experts. In contrast, the Policy Delphi is employed to generate the strongest possible alternative views on the potential resolutions of a major policy issue.

The multi-country Policy Delphi survey, organized by the Centre for Empirical Social Research at the Corvinus University of Budapest within the framework of the INSPIRES research project was held between November 2015 and January 2016. The covered themes included the perception of labour market resilience now and in 2030, the main challenges on the labour market(s) of the European Union in 2030, their potential policy solutions and the future role of the European Union in these processes. ${ }^{1}$ The online Policy Delphi was combined with elements of a backcasting technique to predict policies efficient with regards to perceived future challenges.

In the followings we first present a short overview of theories about policy Europeanization and the current situation of labour market and employment issues. We then describe our methodology and sources, followed by the presentation of the results of the survey, and finally we provide some conclusions.

\section{The European Union and national labour markets}

Since its beginnings, the European integration process can be considered as a process of the reallocation of policy-making competences from the traditional national level towards intergovernmental and supranational arenas (Börzel 2005; Wessels - Kielhorn 1999; Schmitter 1996).

According to the functionalist theory of European integration, the transfer of policymaking competences to the European Union happens when it contributes to more efficient problem-solving or produces better outcome due to the economies of scale (Alesina et al. 2001). Another argument for the reallocation of policy competences is the internationalization process of economies: growing international economic interdependence undermines national governments' ability to control economic actors and transactions in their own territory (Schmidt 2002: 18).

Nevertheless, different policy areas are affected by this process of reallocation to a different extent. Europeanization is more likely to happen in case of policies dealing with problems that require cooperation between countries due to their transnational or cross-border character such as environmental issues or migration (Wessels - Kielhorn 1999). Besides, the convergence of problems between countries, i.e. that all countries are similarly affected by a problem, might also lead to a wish for higher Europeanization, yet to a lesser extent than cross-border problems. Labour market issues, especially unemployment can be considered as

\footnotetext{
${ }^{1}$ We would like to thank Menno Fenger, Romke van der Veen, Marion Ellison, Matthias Knuth, Rik van Berkel, Vittorio Sergi, Nicola Giannelli, László Neumann, Irén Bush and other members of the workshop organized at Corvinus University of Budapest on the 11 February 2016 for their helpful comments, as well as members of the international online Policy Delphi panel and the two anonymous reviewers of this journal.
} 
a policy area where high convergence is achieved over the countries - the problem of unemployment affects all EU member states to some extent, especially during the economic recession following the financial crisis. Labour market and employment questions can in this sense be considered as policy areas with a high degree of convergence along countries (Wessels - Kielhorn 1999: 178). These theoretical suggestions have been empirically confirmed based on surveys conducted among a selected and more informed public: political elites, i.e. members of the European Parliament and members of National Parliaments (Wessels - Kielhorn 1999; Real-Dato et al. 2012).

With increasing levels of unemployment the recent crisis and the following recession further drew the attention to the fragility of the labour markets of the European Union and on the potentially enhanced role of the European Union as a solution (see Figure 1). Both the unemployment rate and thw long-term unemployment rate have increased in the EU since the beginning of the crisis. The unemployment rate has increased from $7 \%$ in 2008 to $10.2 \%$ in 2014, while the long-term unemployment rate doubled (from $2.6 \%$ to $5 \%$ ). In 2014, four countries were especially hit by unemployment with the highest increase compared to 2008: Greece, Spain, Croatia and Cyprus. In general, unemployment increased in all countries except Malta, the UK, Hungary and Germany - where it has even decreased. Long-term unemployment followed similar increasing tendencies except in Finland, Sweden, Hungary, Romania, the Czech Republic, the UK, Luxemburg, Malta and Austria, where its level remained relatively unchanged and Germany where it decreased somewhat. Long-term unemployment is particularly challenging as the longer the unemployment period, the more support is needed the help people's reintegration into the labour market. Long-term unemployment is also a good indicator of the adequacy and success of labour market policies, especially activation measures and the performance of public employment services.

Figure 1. Unemployment and long-term unemployment rates in \% of the active population in the EU by countries in 2008 and 2014

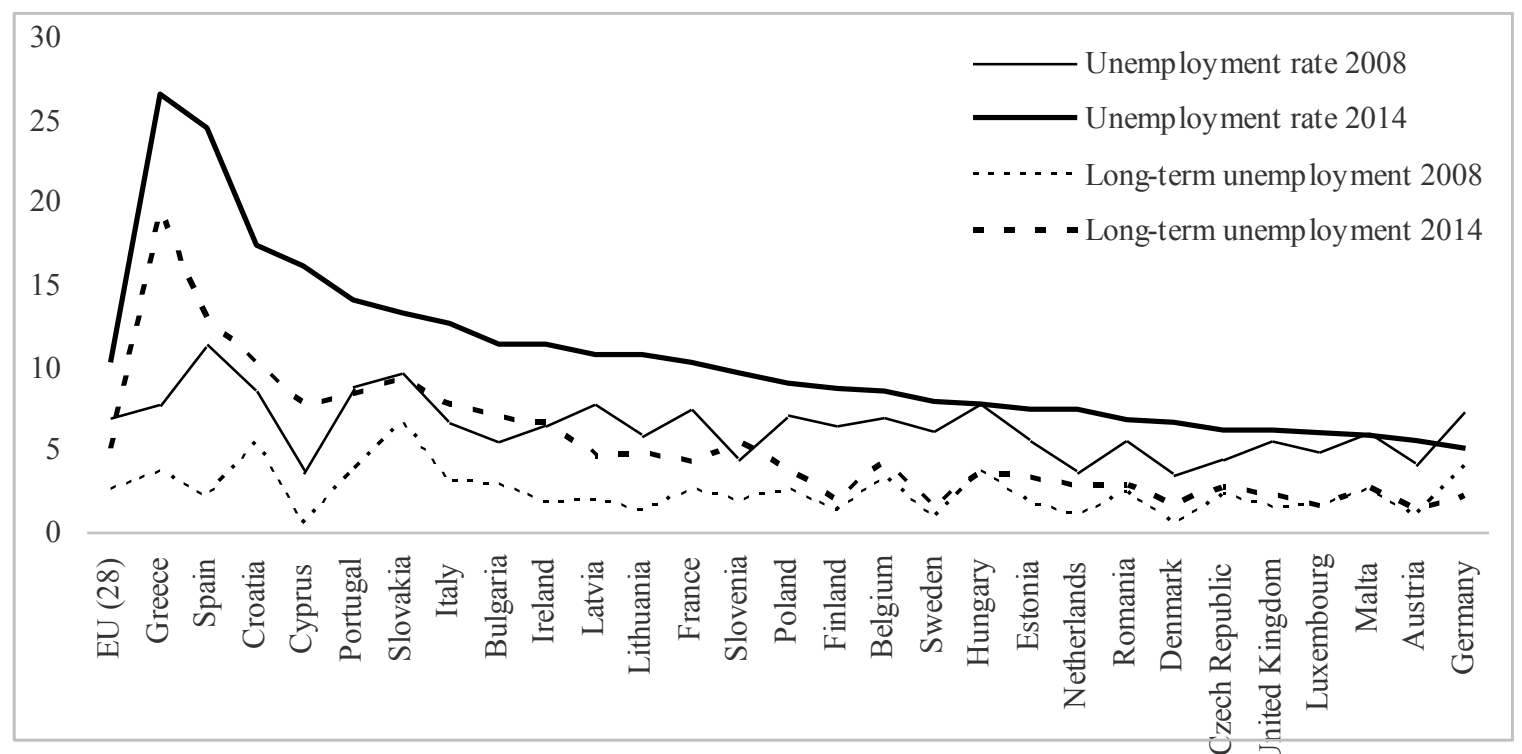

Source: Eurostat Labour Force Survey 
Social policy, including employment issues has nevertheless been considered to be of 'second order importance' in the European integration process. Social policy, which, in the early years of integration focused on the free movement of workers, was rather considered as a market-correcting activity as opposed to economic activity which was the principal aim of the integration process. Domestic adaptation of labour law can, however, be considered as the main field of active EU regulation in social policy (Falkner 2008). Furthermore, the EU has the possibility to promote policy integration in the field through few formal activities. The European Employment Strategy (EES) was adopted in 1997 with the aim to improve labour market performances leading to lower unemployment and higher employment levels. It is based on guidelines, targets, benchmarks and recommendations meaning that the EU has a rather ideological influence on policies and legislation of the member states. In 2000 the Open Method of Coordination (OMC) was introduced as a formal governance instrument of the EES. Since 2005 employment strategies are linked to the economic planning of the EU and of each country which, gives larger influence to the EU economic institutions that became stronger after the crisis.

Nevertheless, labour market policies are primarily a national level competence with important variation in terms of the institutional context, measures, and the level and structure of funding applied. Figure 2 shows the high variability of expenditure by countries on labour market policies (LMP), i.e. public interventions which are explicitly targeted at groups of persons with difficulties in the labour market (the unemployed, the employed at risk of involuntary job loss and inactive persons who would like to enter the labour market). Although in recent decades the general tendency has been an "activation turn", important country differences persist both in terms of the level of spending and the content of measures (Bonoli 2010). In general, new member states from Central and Eastern Europe spend less on labour market policies both in relative (lower \% of the GDP) and absolute terms (lower GDP in general). In Hungary, Sweden and Poland there is a dominance of active labour market policy spending (in Hungary mainly due to the public work program). Nevertheless, active labour market policies (see categories 2-7 on Figure 2) might cover very different policies in terms of their objectives, the tools they use and the way they interact with passive labour market policies (e.g. work incentive reinforcement, employment assistance, direct job creation, training). In other countries such as Cyprus, Italy, Spain and the Netherlands support-kind of LMP spending tend to dominate, while in Romania, Germany, the Czech Republic and Malta services are also important part of the budget.

Figure 2. Expenditure on labour market policies in \% of the GDP in the EU countries in 2014 


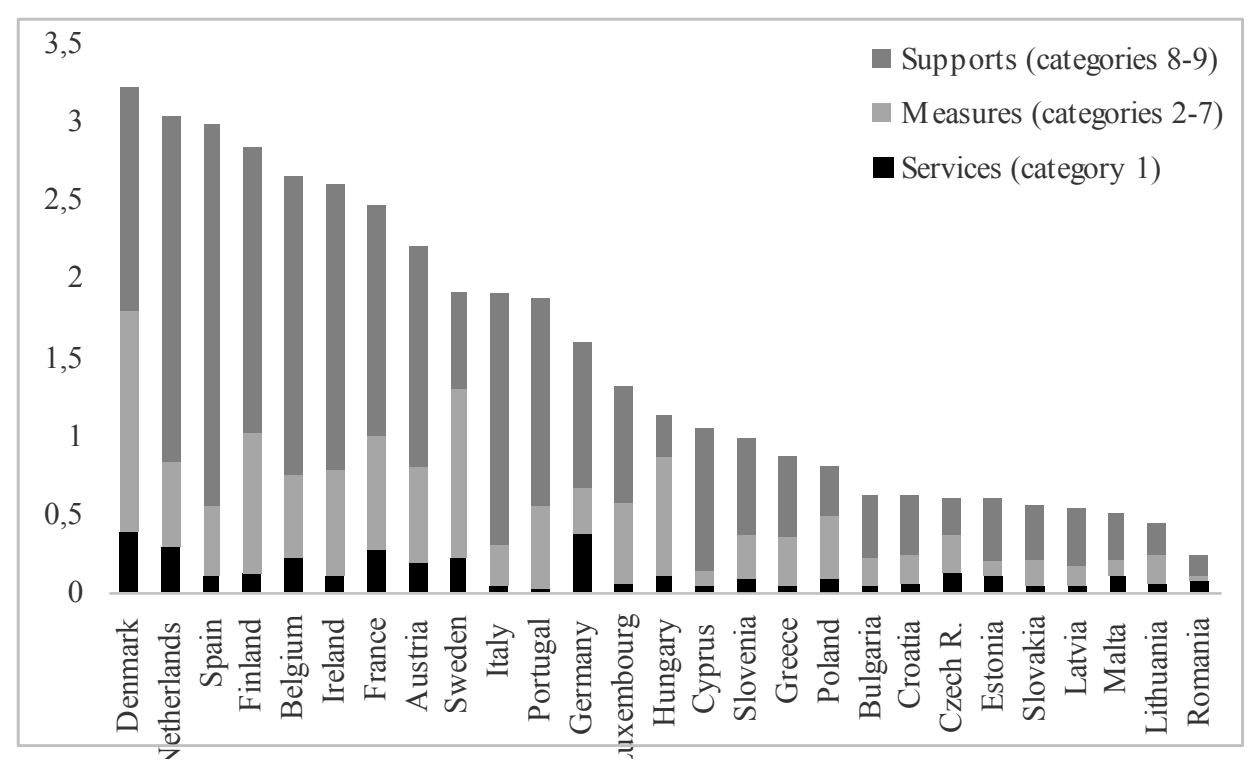

Source: Eurostat, European Commission (DG EMPL)

Notes: LMP services (category 1) cover the costs of the public employment service (PES) together with any other publicly funded services for jobseekers; LMP measures (categories 2-7) cover activation measures for the unemployed and other target groups including the categories of training, job rotation and job sharing, employment incentives, supported employment and rehabilitation, direct job creation, and start-up incentives; and LMP supports (categories 8-9) cover out-of-work income maintenance and support (mostly unemployment benefits) and early retirement benefits.

\section{The methods of online Policy Delphi and backcasting}

Being increasingly used since the 1960s, the Delphi technique can be described as "a method for structuring a group communication process so that the process is effective in allowing a group of individuals, as a whole, to deal with a complex problem" (Linstone - Turoff 2002: 3). Delphi is one of the participative methods aiming to ensure that all relevant possible options have been put on the table for consideration, to estimate the impact, consequences and acceptability of any particular option. Besides the face-to-face version, the virtual or online Delphi is a convenient and efficient method which involves an iterative survey of experts. Each participant completes a questionnaire and is then given feedback on the whole set of responses. With this information in hand, (s)he then fills in a questionnaire again. This feedback from other stakeholders provides additional insight and the participant can potentially revise his or her opinion on the policy strategy, instrument or initiative. The selection of the participating experts is one of the key points of a successful Delphi exercise: informed people, representative of the many sides of the issues under examination need to be chosen.

First introduced in 1969, a Policy Delphi usually includes ten to fifty experts and its main objective is to expose differing positions. Policy Delphi, unlike the traditional one, doesn't need consensus at the end (Slocum 2005); it may even seek to generate the strongest possible opposing views on the potential resolutions of a certain policy issue (Turoff 2002). As opposed to the traditional Delphi method, the Policy Delphi is rather an analytical tool for policy issues and not a mechanism for making a decision. However, it is not a substitute for studies or analyses, but "an organized method for correlating views and information pertaining to a specific policy area and for allowing the respondents representing such views 
and information the opportunity to react to and assess differing viewpoints" (Turoff 2002: 83).The Policy Delphi is a special usage of the Delphi method for the purpose of learning more about policy alternatives, their acceptability and possible consequences (Slocum 2005, Turoff 2002: 83).

In the case of the online Policy Delphi held within the INSPIRES project overall 31 experts filled in the questionnaire in the first round (held between 10 November and 7 December 2015), 27 in the second (held between 1 and 20 December 2015) and 24 in the third round (held between 3 and 27 January 2016). They were stakeholders at regional, national and European level involved in processes of policy making and policy learning in the areas of labour market, employment and social policies. Participating experts came from 11 European countries' government agencies, academia, NGOs, research institutes, there were independent consultants among them, and there was one entrepreneur and a representative of a trade union confederation as well. $^{2}$

The problem of the application of this type of technique is that it tries to deal with policy issues asking experts from many regions and countries, referring to diverse perspectives: core countries (Belgium, Germany, the Netherlands), Southern (Italy, Spain, Greece) and Central-East European countries (Hungary, Slovenia), as well as Sweden, the United Kingdom and - as an indirectly impacted country - Switzerland. National context and peculiarities matter when one analyses factors influencing the effective implementation of different policies: different politics and political contexts, different financial and institutional constraints, different time-frames, and different administrative capacities and techniques are all decisive factors of influence. Therefore, one of the main challenges of this Policy Delphi survey was to remain general enough to be relevant in all the country contexts, but at the same time to avoid being too general to lead to irrelevant outcomes. Nevertheless, putting the focus on the European Union level, the problem induced by different country and organizational contexts could be moderated. Participants formed their opinion on the basis of their expertise, they were not supposed to represent organizational or country interests.

In order to place labour market policies in the EU context, experts were asked to identify the ideal level of policy competence (regional, national, EU, or combinations of these) for a set of labour market issues. In order to make experts to provide evaluation of the future and about what transformations are needed, the Delphi method was combined with a "backcasting" technique (Börjeson et al. 2006). This technique is based on a backward approach which starts with defining a (desirable) future and then works backwards to identify policies and programs that will connect the future to the present. Its advantage is to enable participants to think beyond present cognitive frames (Köves et al. 2013). The backcasting technique often takes form of a scenario study with the formulation of scenarios (sometimes predefined), and the evaluation and improvement of these scenarios in terms of their desirebility, probability, feasibility and coherence (Börjeson et al. 2006, Höjer 1998, Geurs van Wee 2004). However, instead of using scenarios in this research we solely concentrated on exploring future challenges and generation of ideas regarding their policy solutions. Somewhat expanding the frame of the backcasting technique, experts were asked to evaluate labour market resilience, the main challenges and their effective policy solutions in the future,

\footnotetext{
${ }^{2}$ Further information about the sample and questionnaires are available at the authors at request.
} 
2030. These suggested policy solutions were then summed up and tested again in terms of their importance and feasibility. This way our study addressed feasibility and policy implications with regards to perceived future challenges.

\section{The preferred level of policy competences}

In terms of the role the national and regional authorities or the European Union could play, experts were asked about a set of policy domains - like unemployment, immigration, labour market regulation, social protection, education -, focusing at which level they should be dealt with (see Figure 3). Taking into account the character of the issue as well, the most supranational field was immigration where nearly all experts would involve the EU. In the field of labour market regulation and employment policy and law the EU should also be involved according to three quarters of the experts whereas one quarter would keep it in national competence. The treatment of unemployment and education, training, lifelong learning showed similar tendencies, the relative majority would deal with these issues at all three (regional, national and European) levels, many involving European competence, however, the regional character of these issues is also salient.

In the second round of the survey, we mentioned the three most frequently given answers in the first round concerning the five policy fields respectively. We asked the experts to evaluate again the options in the light of this information. As a general tendency the experts further strengthened the relevance of the options which had been already emphasized. It was especially true in the case of single-options (national, regional, or European level). In the case of combined options there were policy fields - like unemployment and education - where the originally high popularity of the answer has been increased further. In other policy fields migration, labour market regulation, social protection, where they were the second most frequently chosen solutions - the original popularity decreased. As a consequence the experts' opinion became more focussed. They emphasized the role of national government in the case of unemployment, labour market policy, social protection and education. Among the single answers the EU got more emphasis not only in the case of immigration, but also in the case of unemployment (while its proportion decreased in labour market regulation and social protection). The regional level as a single option, as well as in combination with the national government or the EU, was less popular, except for the handling of unemployment and education. Combined national and EU solutions grew in popularity in the field of labour market regulation and social protection, where they were originally the most supported solutions.

Figure 3. Preferred level to deal with policy areas $(\%)\left(\mathrm{n}_{\text {round } 1}=31, \mathrm{n}_{\text {round } 2}=27\right)$ 


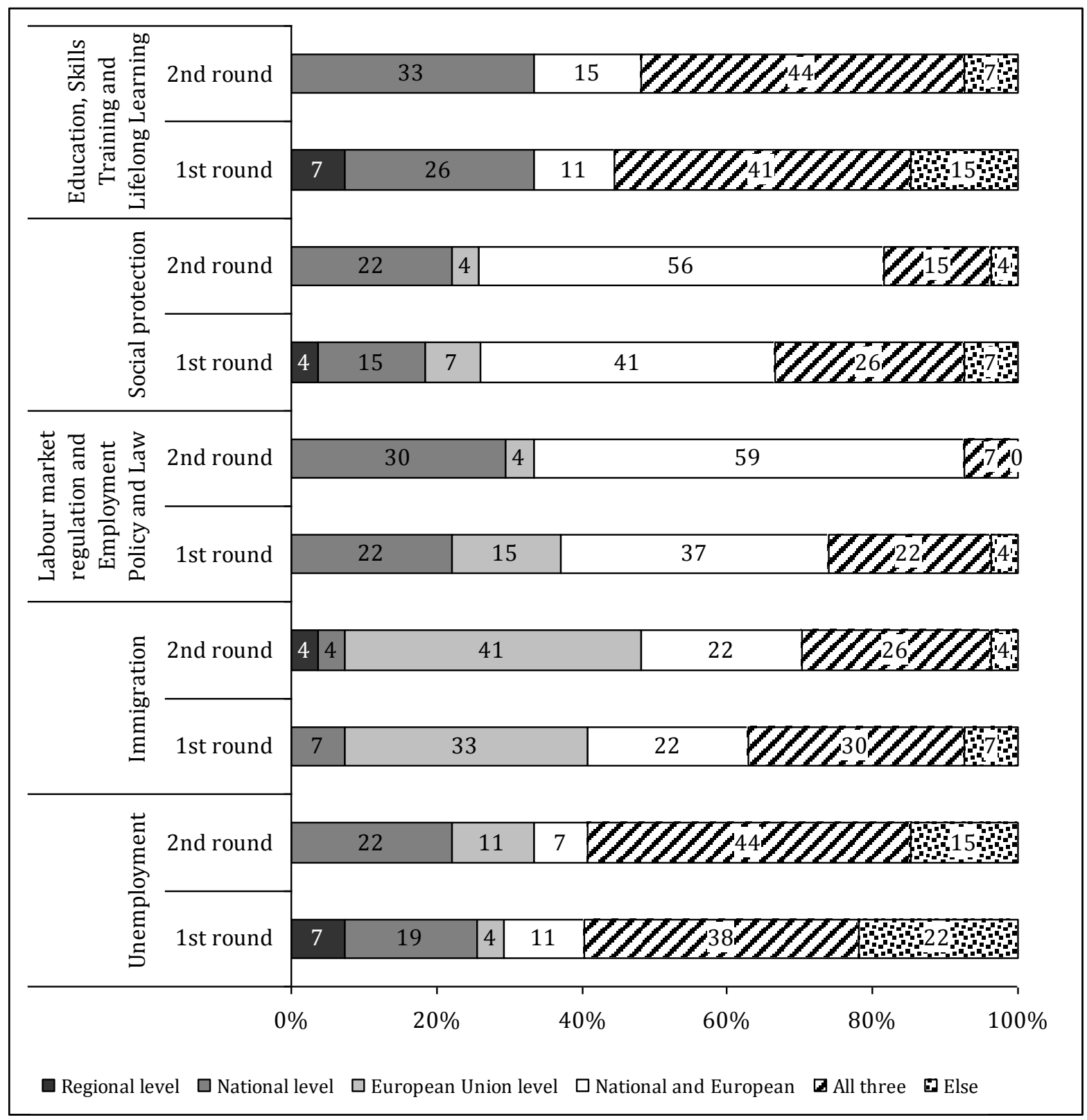

Note: the exact wording of the question was in the first round: "How do you think it would be most appropriate to deal with each of the following policy areas? Do you think that [area]... should be mainly dealt with at regional level, at national level, at European Union level?". In the second round, the wording was: "In the boxes below we mention the 3 out of 8 options which got the highest rate in the first round. You may choose any of the 8 options, but we are wondering that in the light of this information, how do you think it would be most appropriate to deal with each of the following policy areas? Do you think that [area] should be mainly dealt with at regional level, at national level, at European Union level?'

In the third round of the survey, we asked on an extended list of policy areas (including the previous ones) how important and how feasible the involvement of the EU would be in the next 15 years (see Figure 4). The policy domains where the long term involvement of the EU seems to be the most important are the problems of immigration, environment, unemployment and regulation of the financial sector. The feasibility of the involvement of the EU into these policies is also above the average according to the experts. In the case of immigration and unemployment, there is a significant connection between importance and feasibility, but this is not the case in environmental and banking policies. Generally, feasibility lags behind 
importance. The importance of education, economic policy, labour market regulation, social protection and fighting against crime are evaluated as „rather important” on the average and their feasibility is between rather feasible and not feasible. Involvement of the EU into health care policy is evaluated as relatively less important and less feasible.

As it turns out, the EU's involvement would be most important in policy issues dealing with problems crossing borders, such as environmental issues and immigrations which is in line with the globalization of problems hypothesis of Wessels and Kielhorn (1999: 177). Experts' evaluation of the involvement of EU in unemployment issues (evaluated as the third most important after the previous issues) may reflect the previously mentioned convergence of problems logic. These are followed by more economic issues, which may reflect functional needs: according to an instrumental argument policy-making should be transferred to the European Union in the hope that it contributes to better problem solving (Gabel - Anderson 2002; Gabel 1998), while more expensive policies would be kept in national competence (Hooghe 2003). On the other hand, the involvement of the EU in issues directly related to welfare or of a social character (issues involving larger budgets, such as social protection and health care), together with their regulation, would be less important according to experts. These latter issues, where the EU'S role was seen as less important, are also the issues where the EU involvement is seen as the less feasible.

However, policy preferences are not independent from the national context. Previous studies confirm the influence of the character of welfare state (Hooghe - Marks 2005), or the mediating effect of the national labour market (Brinegar - Jolly 2005) on the formation of policy preferences.

Figure 4. Importance and feasibility: long term involvement of the EU (mean 1-4, \pm standard deviation)

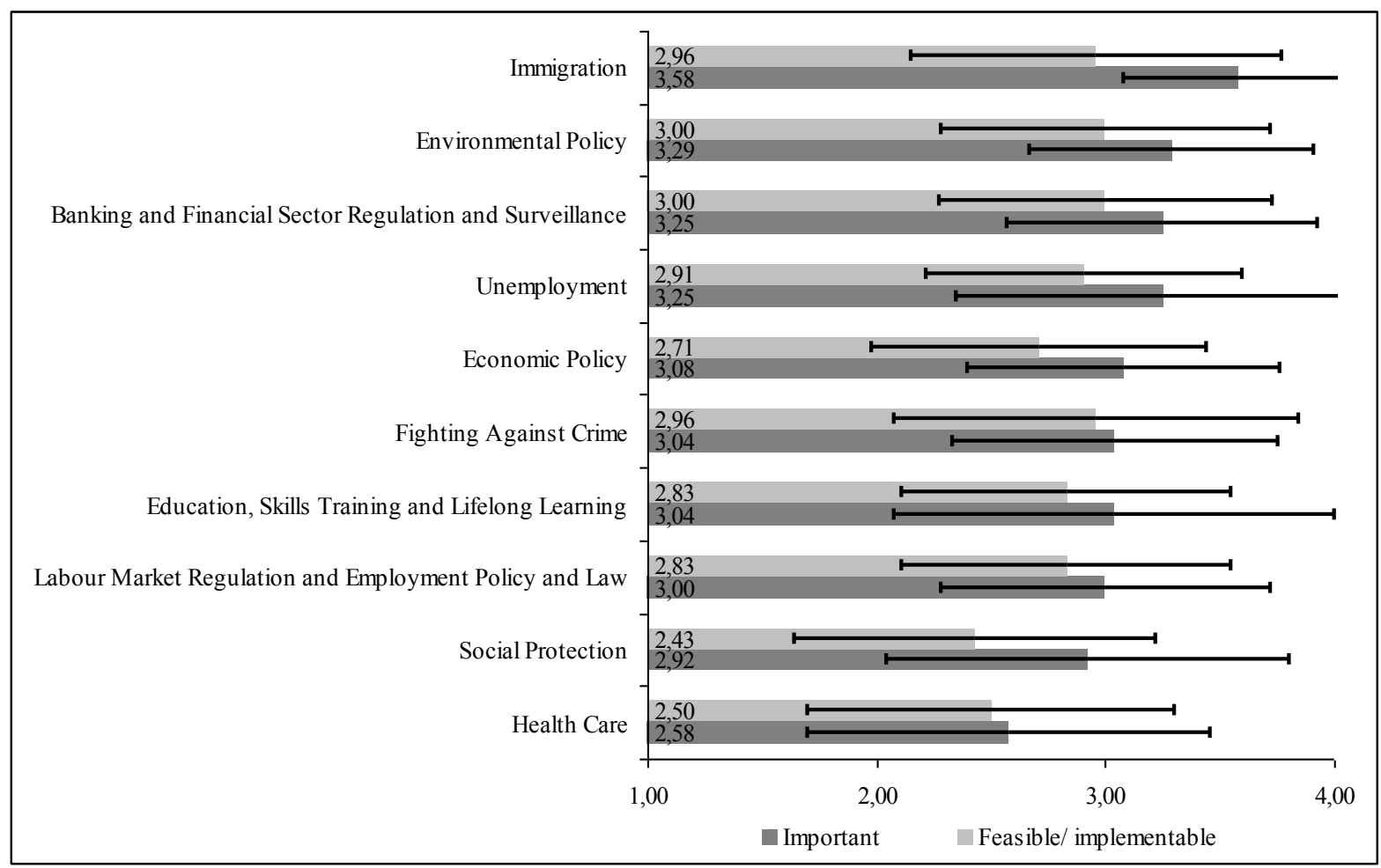


Notes: $\mathrm{n}_{\text {round }}=24$. The exact wording of the question was (in the $3^{\text {rd }}$ round): "How important or unimportant/feasible or unfeasible would the greater involvement of the EU in the following policy fields be in the next 15 years according to your opinion?"

4=Very important/ Totally feasible, $1=$ Not important at all/ Not feasible at all

\section{Labour market resilience, main challenges and their policy solutions in $\mathbf{2 0 3 0}$}

\subsection{Perception of labour market resilience}

Labour market resilience was defined as the inclusive capacity of the system to resist, withstand or quickly recover from negative exogenous shocks and disturbances and to renew, adjust or re-orientate in order to benefit from these shocks. Expert opinions were rather divided on the issue in the first round of the survey: equal share of experts perceived their country to be resilient or not resilient (50-50\%) while the European Union was seen slightly less resilient than the country average by $43 \%$ perceiving it as resilient versus $57 \%$ saying it is not (see Figure 5). In the subsequent rounds of the survey, after providing experts with the answers of the other experts, the perception of the labour market resilience of the EU did not change significantly, however, perceptions of the resilience of the country of residence changed somewhat, with perceptions becoming increasingly positive. In terms of the perception of the resilience of their country of residence, German, Belgian, Swedish and Swiss experts were rather positive, Greek, Italian, Slovenian and Spanish experts rather negative, while British, Dutch and Hungarian experts rather divided. Sometimes the resilience of the European Union as a whole was seen as the opposite of the country of residence: the EU had a negative perception in the case of positive country evaluation (e.g. Belgium, Germany and Switzerland), or the EU had a positive perception in the case of negative country evaluation (e.g. Slovenia).

Figure 5. The expected and perceived labour market resilience in the EU (mean 1-4, \pm standard deviation) 


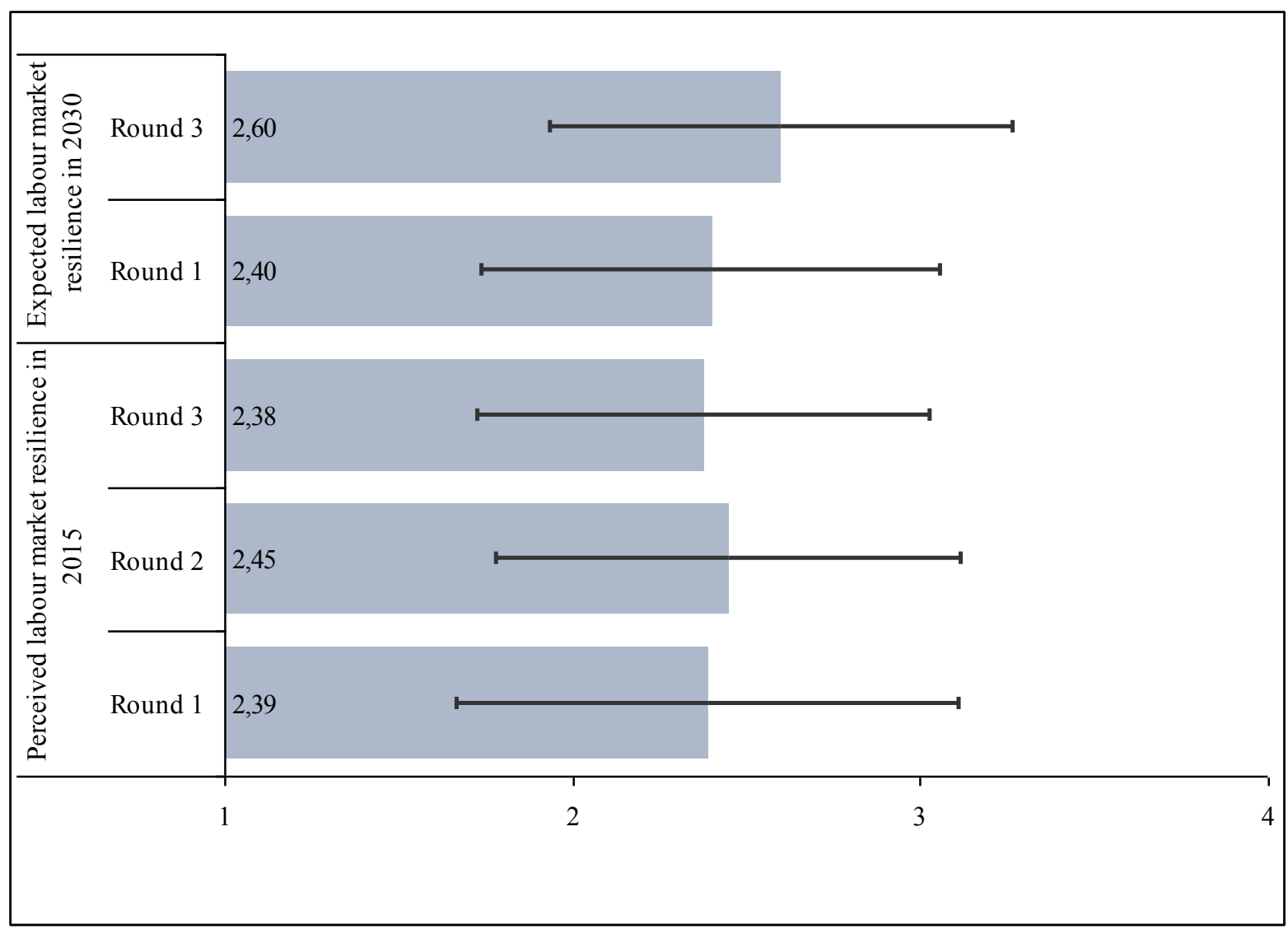

Notes: $\left(\mathrm{n}_{\text {round1 }}=31, \mathrm{n}_{\text {round } 2}=27, \mathrm{n}_{\text {round3 }}=24\right.$. The exact wording of the question was "How would you rate the labour market resilience of the European Union as a whole?" and "How would you think the labour market resilience of the European Union as a whole will change until 2030?” 4= Very resilient/ Much more resilient, 1= Not resilient at all/ Much less resilient

Experts were also asked to forecast the future of the labour market until 2030. Evaluations of labour market resilience in the future, just as in the case of opinions on the present resilience, were rather divided. Slightly more than half of the experts foresaw a more resilient labour market in their country and less than half in the EU. Individual countries were better perceived than the European Union as a whole. Overall, German, Hungarian, British and Swiss experts were rather positive in terms of their country's labour market resilience in the future, Greek experts were rather negative.

In the third round, we asked the question again and the answers were partly different. As to the labour market resilience of their own country, the opinion hasn't been changed significantly. However the former pessimism turned into optimism concerning the EU's long term labour market perspectives: three out of five experts think that in the long run the resilience will improve. The most likely reason is that there is a greater uncertainty concerning the evaluation of supranational developments than national ones. Another factor is that in the second round experts were supposed to spell out important policies which could lead to the long term improvement of EU's labour market resilience. Thinking over the alternative solutions and measures - even if there were doubts about the feasibility of some of them - might have had a side effect, namely that experts started to develop a less gloomy vision of long term supranational future. 


\subsection{Main challenges and their policy solutions in 2030}

The main challenges that the labour market in the European Union will face until 2030 according to experts were first defined with an open-ended question in the first round of the survey. After having the answers summarized, a list of the main challenges was tested in the second round of the survey. Experts found that the most important challenge that the EU will be facing in 2030 will be unemployment - 15 out of 24 experts considered it as a very important challenge. This was followed by inequalities between countries and problems of ageing. Experts differentiated between immigration from third countries and intra-European migration, the latter being much less considered as an important challenge.

Figure 6. Importance of the main challenges on the labour market in the European Union until 2030 (mean 1-4, \pm standard deviation)

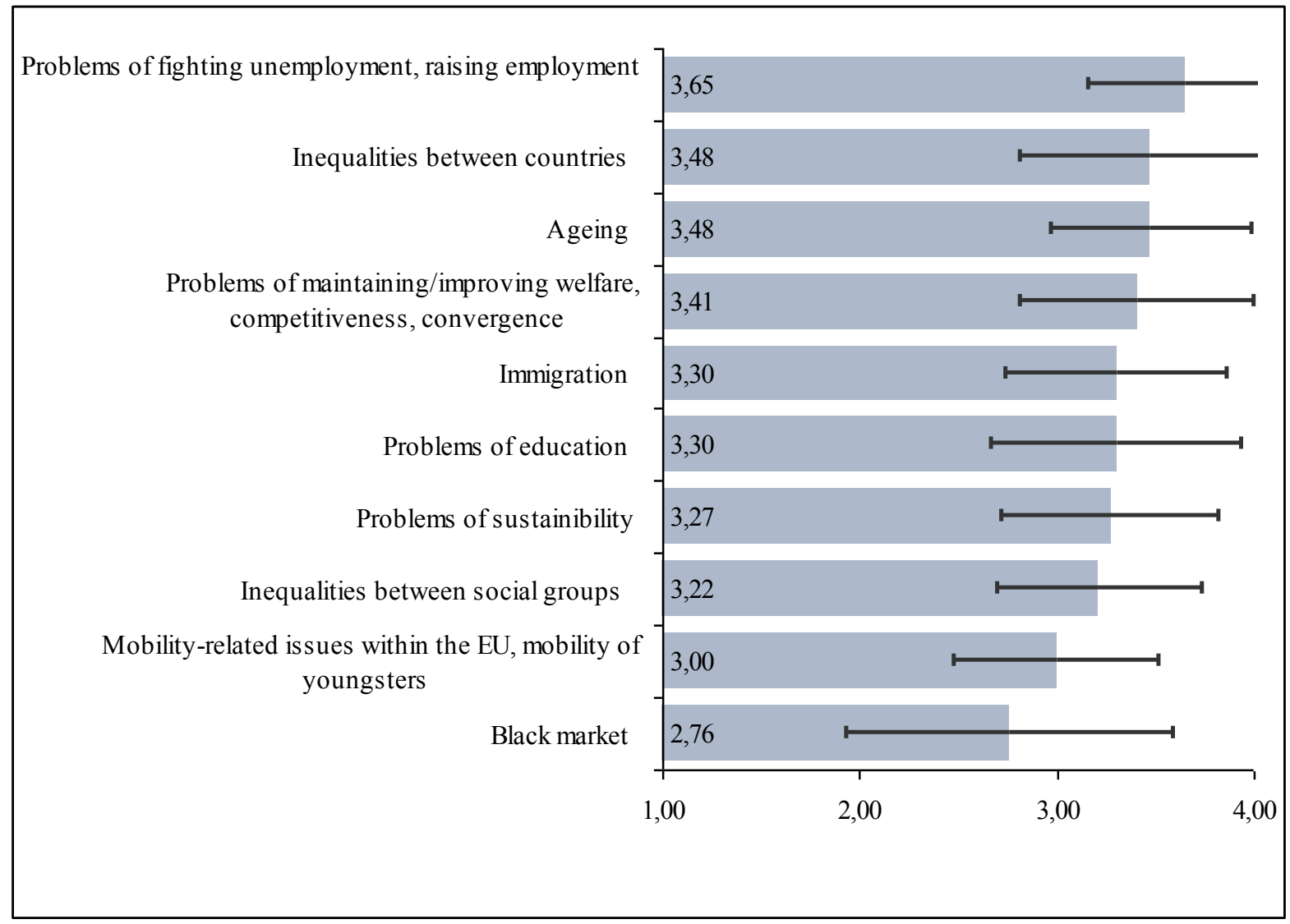

Notes: $\mathrm{n}_{\text {round } 2}=27$. The exact wording of the questions were (in the second round): "We have summarised the different answers about the main challenges on the labour market in the European Union as a whole until 2030 in the following list. For each item please indicate how important you consider them as a challenge on the labour market in the EU." 4=Very important, 1=Not important at all

In the second round, we have summarised in 12 items the different answers experts had given in the first round about the policies considered to be best suited to deal with the main challenges of the labour market in the EU until 2030. These umbrella categories included items like strengthening EU-policies and institution, sustainable methods, improvement of social policy. In the next wave we asked them to indicate how important and to what extent feasible/implementable they consider these solutions in the long run. 
As it turns out from this, in the long run the most important policies according to the experts are education, investment in human and social capital and improvement of social policies and protection, including migration policy. This is followed by - somewhere between the very important and rather important categories - the need for social inclusion, strengthening EU-policies and common policy reforms, stopping austerity policy. Flexicurity and a new contract concerning rights and responsibilities of citizens were considered as being rather important as well on the average. Strengthening trade unions and creating low quality jobs via polarization of the labour market are placed somewhere between the rather important and rather not important options, which was due to the divided opinion of experts. The experts considered most of these policies rather feasible as well, but averages of feasibility were always lower than importance. Common policy reforms and stopping austerity policy were between the rather not feasible and rather feasible options.

In principle incongruence of importance and feasibility could happen due to very different reasons (there could be unimportant and at the same time implementable solutions among others), but the results show that in most of the cases it refers to a situation where importance of policy changes is highly, while feasibility is not so highly evaluated by the experts. Why this gap occurs frequently deserves further investigation. The reasons might be manifold again, low level of adaptability of national policy makers being but one of them. However, looking at the results more closely it occurs that in many cases statistical insignificance is due to the difference of intensity and not difference of direction. It is a frequent reason that a policy is evaluated as very important and not very much feasible, just "rather feasible". In the cases of the most important policies in experts' mind - education, social policy and protection, including migration policy and investment in human and social capital - the feasibility is among the highest as well and there is a significant connection between importance and feasibility.

Figure 7. Expected importance and feasibility of long term future policies (mean 1-4, \pm standard deviation) 


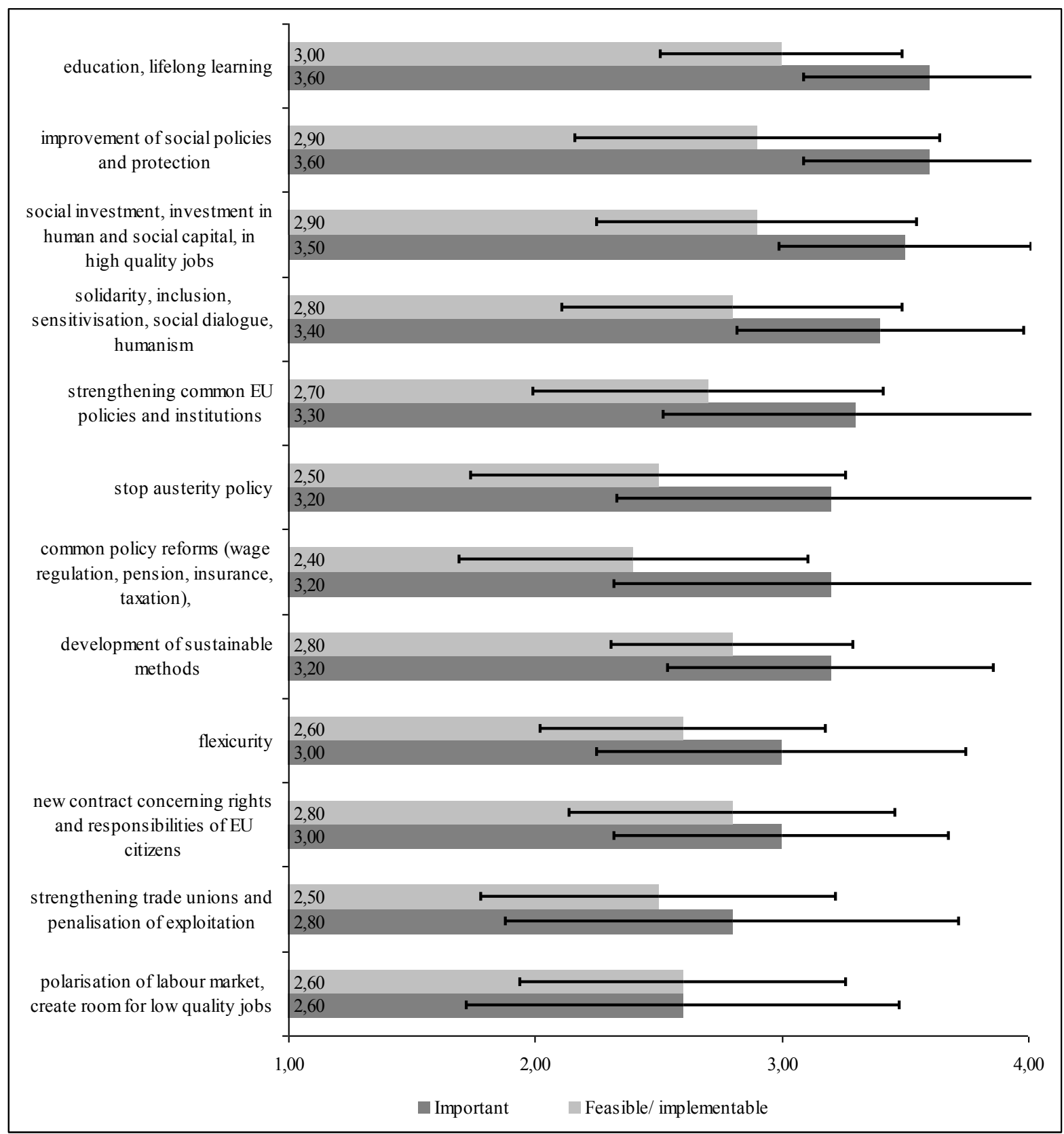

Notes: $\mathrm{n}_{\text {round2 }}=27$. The exact wording of the questions were (in the second round): "For each item please indicate how important you consider them as a potential solution for the challenges on the labour market in the EU in 2030." and "How much do you think these potential policy solutions are feasible/ implementable?"

4=Very important/ Totally feasible/implementable, $1=$ Not important at all/ Not feasible/implementable at all

In the second round of the survey the three-quarter majority of experts agreed upon that common policy reforms (wage regulation, pension, insurance, taxation) might be an important potential solution for the challenges of the labour market in the EU until 2030. However, only one-third thought that it is feasible as well. In the third round, we asked experts to spell out how these could be implemented in spite of eventual constraints. The majority remained sceptical about the feasibility of such policy reforms for several reasons. One point was that the EU is too much an elitist project (Haller 2008) and there is distrust on behalf of voters toward this. Another point was the heterogeneity of the countries and historical differences in 
regulation practices. Some concluded that the current regulation should not be changed, since common regulation often leads to administrative "overkill".

\section{Conclusion}

Policy Delphi can be considered as an analytical tool generating possibly opposing viewpoints of experts on a certain policy issue. It is different from an expert survey as it contains several rounds of questions and allows for changing views through the consideration of others' opinion. Nevertheless, the results of such a research might also be used by policy makers: our research has the advantage to draw the attention to current and future problems related to labour market resilience, it might provide ideas for potential policy solutions and these are assessed in terms of their feasibility as well.

According to experts, the EU's involvement would be the most important in policy issues dealing with problems of a cross-border character such as immigration or environmental issues. However, favourable opinions on the inclusion of the European level (besides regional or national competences) in dealing with unemployment issues increased somewhat from the first to the second round of the survey similarly to the domain of education, training and lifelong learning. While preferences for the joint national and European competences in labour market regulation and social protection also increased. In this sense the EU's role is rather seen as positive and the Policy Delphi also led to a convergence of experts' opinion.

Evaluation of labour market resilience until 2030 was rather divided: about half of the experts were positive about their country's future resilience, the other half were not. Less than half of them were positive regarding the chances of EU's long term labour market resilience, however this increased in the third round of the survey.

Unemployment is considered to be one of the most important challenges the EU will be facing in the future. In terms of the policies considered to be best suited to deal with the main challenges of the labour market in the EU until 2030, the most important policies according to the experts are education, investment in human and social capital and improvement of social policies and protection, including migration policy.

When there is a gap between importance and feasibility - and this is a frequent case in this set of questions - it means that there is incongruence between vision and practice of policy making. This was the case with common policy reforms in the European Union according to Delphi panellists.

The majority of experts stressed the importance of common policy reforms, although remained divided in terms of how to do and what to do. As for how to do reforms, a slight majority argued for graduality and convergence, agreeing upon in guiding principles first, followed by a slower fine tuning process, dividing the complex problems into steps with clear priorities. Others argued that only a crisis-driven shock, a "hard time effect" (Gourevitch 1986) is able to change the dominant political pact, or persuade national governments to adjust their policies especially in highly protective countries.

As far as what to do is concerned, three main types of deeds could be discerned. First, there is a wide range of arguments emphasizing the connection between politics and policy. In these views substantive changes in politics were emphasized as precondition of successful common policy reforms. The EU government should be directly elected, with a common 
budget policy and with the cancellation of the consent-based decision making system of the European Council. Shifting towards a higher level of supranational redistribution and a federalist solution instead of an intergovernmentalist one seem to be inevitable preconditions of successful policy reforms in the fields of labour market, pension, taxation and wage regulation according to these opinions. The second type of solutions did frame labour market policy issues in a wider social policy context. These mentioned the equalizing impact of promoted mobility and improved incentives including housing support, child care and training programs. A third group of suggestions - whi h could be called process-based views emphasized the technicalities of analysis and monitoring in the implementation of successful common policy reforms.

\section{References}

Alesina, A. - Angeloni, I. - Schuknecht, L. (2001): What Does the European Union Do? Harvard Institute of Economic Research Discussion Paper 1935.

Bonoli, G. (2010): The political economy of active labour market policy. Politics \& Society 38(4): 435-457.

Börjeson, L. - Höjer, M. - Dreborg, K-H. - Ekvall, T. -Finneveden, G. (2006): Scenario types and techniques: Towards a user's guide. Futures 38: $723-739$.

Börzel, Tanja A. (2005): Mind the gap! European integration between level and scope. Journal of European Public Policy 12(2): 217-236.

Brinegar, A. P. - Jolly, S. K. (2005): Location, Location, Location. National Contextual Factors and Public Support for European Integration. European Union Politics 6(2): $155-180$.

Falkner, G (2008): Social Policy. In: Graziano, P. - Vink, M. P. (eds.): Europeanization. New Research Agendas. Basingstoke: Palgrave Macmillan, pp 253-265.

Gabel, M. J. (1998): Public Support for European Integration: An Empirical Test of Five Theories. Journal of Politics 60(2): 333-358.

Gabel, M. J. - Anderson, C.J. (2002): The Structure of Citizen Attitudes and the European Political Space. Comparative Political Studies 35(8): 893-913.

Geurs, K. - van Wee, B. (2004): Backcasting as a Tool for Sustainable Transport Policy Making: the Environmentally Sustainable Transport Study in the Netherlands. European Journal of Transport and Infrastructure Research 4(1): 47-69.

Gourevitch, P. (1986): Politics in Hard Times. Comparative Responses to International Economic Crises. Ithaca: Cornell University Press.

Haller, M. (2008): European Integration as an Elite Process. The Failure of a Dream? Routledge: New York.

Hooghe, L. (2003): Europe Divided? Elites vs. Public Opinion on European Integration. European Union Politics 4(3): 281-304.

Hooghe, L. - Marks, G. (2005): Calculation, Community and Cues. Public Opinion on European Integration. European Union Politics 6(4): 419-443.

Höjer, M. (1998): Transport Telematics in urban systems - a backcasting Delphi study. Transportation Research 3(6): 445-463. 
Köves, A. - Király, G. - Pataki, G. - Balázs, B. (2013): Transition to Sustainable Employment: Using Backcasting Technique for Designing Policies. Managing Global Transitions 11(2): 119-139.

Linestone, H.A. - Turoff, M. (2002): Introduction. In: Linestone, H.A. - Turoff, M. (eds): The Delphi Method. Techniques and Applications.

http://is.njit.edu/pubs/delphibook/delphibook.pdf (retrieved 30/01/2016)

Real-Dato, J. - Lengyel, G. - Göncz, B. (2012): National elites' preferences on the Europeanization of policy making. In: Best, H. - Lengyel, G. - Verzichelli, L. (eds): The Europe of Elites. A Study into the Europeanness of Europe's Political and Economic Elites. Oxford: Oxford University Press.

Turoff, M (2002): The Policy Delphi. In: Linestone, H.A. - Turoff, M. (eds.): The Delphi Method. Techniques and Applications. http://is.njit.edu/pubs/delphibook/delphibook.pdf (retrieved 30/01/2016)

Schmidt, V.A. (2002): The Future of European Capitalism. Oxford: Oxford University Press. Schmitter, P.C. (1996): Imagining the Future of the Euro-Polity with the Help of New Concepts. In: Marks, G. - Scharpf, F.W. - Schmitter, P.C. - Streeck, W. (eds): Governance in the European Union. London: Sage.

Slocum, N. (2005): Delphi. In: Steyaert, S. - Lisoir, H. (eds): Participatory Methods Toolkit. A practitioner's manual. King Baudouin Foundation and the Flemish Institute for Science and Technology Assessment

Wessels, B. - Kielhorn, A. (1999): Which Political Competencies for Which Political Level? In: Katz, R.S. - Wessels, B. (eds): The European Parliament, the National Parliaments, and European Integration. Oxford: Oxford University Press. 